\title{
Examining the Relationship between Hope and Attachment: A Meta-Analysis
}

\author{
John Blake1, Christine Lynn Norton ${ }^{2}$ \\ ${ }^{1}$ Rehabilitation Psychology \& Special Education, University of Wisconsin-Madison, Madison, USA \\ ${ }^{2}$ School of Social Work, Texas State University, San Marcos, USA \\ Email: jpblake@wisc.edu, cn19@txstate.edu
}

Received 9 February 2014; revised 5 March 2014; accepted 1 April 2014

Copyright (C) 2014 by authors and Scientific Research Publishing Inc.

This work is licensed under the Creative Commons Attribution International License (CC BY).

http://creativecommons.org/licenses/by/4.0/

c) (i) Open Access

\begin{abstract}
The authors report quantitative findings from a meta-analysis of studies investigating the relationship between attachment style, grounded in theory developed by Bowlby and Ainsworth; and Snyder's theoretical model of hope (Ainsworth \& Bowlby, 1991; Snyder, 1994). Statistically significant results provide support for further investigation of clinical value of the attachment/hope dynamic as an effective heuristic for conceptualizing human development, behavior and the therapeutic process.
\end{abstract}

Keywords

Attachment Style, Hope Theory, Meta-Analysis

\section{Introduction}

Recent literature documents the need for a theoretically cohesive paradigm of evidence-based practices that are appropriate for use in contemporary clinical settings that do not incorporate the prolonged course of treatment or "50-minute hour" associated with the traditional psychotherapeutic milieu. Helping professionals, such as social workers, rehabilitation counselors and clinical mental health counselors, require empirically valid, theoretically grounded interventions that are effective, flexible, and can be implemented in a relatively brief time frame (Olney, 2009). A related challenge involves the integration and empirical validation of pragmatic theoretical models (Chan, Tarvydas, Blalock, Strauser, \& Atkins, 2009). Theory-driven research that contributes to the development of actionable, evidence-based practices is enhanced when research literature 1) reconciles new conceptual models with established theory, 2) utilizes theoretical concepts to simplify complex behavioral and clinical dynamics, 3) presents parsimonious, well organized accounts of theoretically-driven findings, 4) contributes to a conceptualization of theories as comprehensible heuristics that are applicable to a broad range of dynamics, 5) acknowledges the development of theoretical knowledge as a shared enterprise in which a collection of fluid 
concepts benefit from change and amendment, and 6) aligns with practical, clinical implementation (Dunn \& Elliott, 2008).

The field of positive psychology represents one approach to theory-driven research and practice that is consistent with these criteria, which focuses on human strengths and capacity (Lopez \& Snyder, 2011). In positive psychology research, investigated constructs are conceptualized as assets that aid in healthy human development and resilience, several of which are explored in this study. The purpose of this paper is to report quantitative findings from a meta-analysis of studies focused on the relationship between attachment style, and Snyder's theoretical model of hope (Ainsworth \& Bowlby, 1991; Snyder, 1994). Attachment style is grounded in the comprehensive, psychodynamic theory of personality development developed by Bowlby and Ainsworth, while Snyder's model provides afoundation for a range of empirically supported, brief, targetedinterventions (Ainsworth \& Bowlby, 1991; Snyder, 1994; Snyder, Lehman, Kluck, \& Monsson, 2006). The impetus formeta-analyticinvestigation of the relationship is grounded in the clinical value of the attachment/hope dynamic as an effective heuristic for conceptualizing human development and behavior.

Two central assumptions of the attachment framework are 1) the quality of early relationships is predictive of individuals' social-relational patterns across the lifespan, and 2) these attachment patterns are essentially stable in adulthood (Fraley, Vicary, Brumbaugh, \& Roisman, 2011). Moreover, while there is a strong body of literature linking attachment patterns to various measures of adjustment and well-being, there are fewer studies focused on testing the efficacy of potential mediators of maladaptive attachment style (Lopez, Mauricio, Gormley, Simko, \& Berger, 2001). A comprehensive account of Snyder's hope theory was published roughly 26 years after Bowlby's definitive volume on attachment. Snyder delineates a relationship between hope and attachment in which early attachment relationships predict adult levels of hope, with healthy early attachment relationships contributing to individuals' ability to manifest goal-directed thought and overall hopefulness (Bowlby, 1969; Snyder, 1994). Empirical findings related to the malleability of hope indicate that levels of dispositional hope may be amenable to intervention (e.g., Cheavens, Feldman, Gum, Michael, \& Snyder, 2006; Davidson, Feldman, \& Margalit, 2012). Furthermore, studies investigating the hope construct have indicated that many attachmentassociated outcomes that are operationalized inhuman service research and practice are also linked to the hope construct (e.g., Chan, Chan, Ditchman, Phillips, \& Chou, 2013; Davidson et al., 2012; Schiff \& Levit, 2009). Investigation of the relationship between attachment and hope could provide a foundation for increased utilization of Snyder's hope theory as a model that is applicable across broad range of helping professions.

In this meta-analysis, attachment is positioned as the independent variable, with hope situated as the dependent variable. It should be noted however, that data included in the analysis are correlational, and that the IV-DV designation is informed by theoretical conceptualization. In this context, the alternative hypothesis is that correlational data will provide support for Snyder's (1994) theoretical conceptualization in which attachment style, as a function of relationships with primary caregivers during infancy and childhood, predicts levels of hope in adulthood.

\section{Literature Review}

Attachment theory provides an ethological account of personality development in which early caregiver responses during infancy influence enduring patterns of social interaction across the lifespan. The model is centrally informed by Bowlby and Ainsworth's observation that the human drive for intimate, close relationships is a biologically grounded trait that has been evolutionarily selected for advancement of the human species (Ainsworth \& Bowlby, 1991). Along these lines, the quality of infants' social attachment relationships with their early caregivers is the primary predictor of the relative health of personality development (Ainsworth, Blehar, Waters, \& Wall, 1978).

Snyder's theory accounts for the relative optimism of individuals' narratives of future events and entails a cognitive/affective model comprised of two central cognitive/affective processes tied to goal achievement: 1) pathways thoughts, which are related to self-appraisal of the cognitively-based ability to identify potential routes to achieve goals, and 2) agency thoughts, which are self-appraisal of the capacity to implement pathways and provide the motivational drive toward goal achievement (Snyder, 2002). Importantly, while each construct describes a corresponding ability (planning, in the case of pathways; determination, in the case of agency), the model is centrally informed by self-appraisal. Relative to pathways thoughts, the construct represents cognitive abilities to evaluate goal scenarios, develop plans, and shift between multiple potential plans. Because Snyder's 
theory is informed by the notion that individuals' beliefs about their abilities are determinant, the relative presence of the ability (i.e., high pathways or low pathways) is defined in terms of self-evaluation. The reflexive component of the agency thoughts construct is perhaps less salient, considering that there is likely a high degree of redundancy between individuals' beliefs about their level of motivation and their actual level of motivation, nevertheless "the defining characteristic of hope is the perceived capacity to produce these components [italics added]” (Snyder et al., 2006: p. 89).

Hope theory entails a developmental conceptualization in which individuals' levels of hope during childhood, adolescence and adulthood are directly related to the relative health of attachment patterns initiated during infancy. Snyder's articulation of the attachment/hope dynamic suggests a bifurcated mechanism in which the attachment relationship and the environment that springs from the attachment relationship are separately and concurrently facilitative of hope (Snyder, 1994).

Healthy early attachment relationships include sensitive, reliable attendance and responsivity to infants' needs, thus engendering self-awareness and attentiveness. In turn, attributional self-awareness, specifically awareness of one's self as a distinct entity and attentiveness to one's environment, is identified by hope theory as components inherent in goal directed thought. Additionally, early caregiver relationships rooted in responsive, effective care provide infants with an early model of hopeful behavior. Finally, because interaction between early caregivers and infants provides the blueprint for subsequent social interactions, early relationships are predictive of the degree to which infants' internalized social schemas are aligned with healthy, hope-nurturing social interaction (Snyder, 2002).

Drawing on Erikson, Snyder suggests that during the first year of life, development is geared toward infants' ascertainment of whether they can "trust the world". Early relationships that satisfy needs for contact and caring and contribute to dependable, stable environments, allow infants to determine that the world can be safely trusted. Like healthy attachment, hope is one result of this early establishment of trust (Snyder, 1994).

\section{Method}

The focus of the present research is quantitative investigation of the overall effect size of the relationship between attachment, as conceptualized by the Bowlby/Ainsworth framework and hope, as conceptualized by Snyder's model. Because aggregate findings related to hope and attachment have been generated by studies focused on a diversity of research questions, the present review is concerned with extracting specific findings related to the hope/attachment relationship. Meta-analysis provides a framework for integrating studies with diverse fociwhen the meta-analyzed studies share a common variable (Bangert-Drowns, 1997).

\subsection{Study Selection}

Studies were identified through the electronic databases PsycINFO, ERIC, and Education Full Text. The keywords attachment and hope were searched with the initial search producing 694 results. Results were limited to Scholarly (Peer Reviewed) Journals, which returned 409 articles. Results were further limited to quantitative study, and full text, which returned 34 articles. Thirty-four articles were reviewed for inclusion of: 1) focus on the relationship between individuals' attachment and levels of hope; 2) inclusion of attachment conceptualization that is consistent with Bowlby/Ainsworth framework; 3) inclusion of a hope conceptualization that is consistent with Snyder framework; and 4) inclusion of product-moment coefficient (Pearson's $r$ ) for hope/attachment relationship. Eight studies were identified through this procedure.

Preliminary analysis of the eight studies indicated that the aggregate data included in the studies was insufficient for generating meaningful analytic findings related to the target relationships $(N=2027$, with six studies including investigation of the relationship between hope and anxious attachment, six studies including investigation of the relationship between hope and avoidant attachment, and five studies including investigation of the relationship between hope and secure attachment). Criteria for study inclusion were re-examined and amended in order to capture a broader accounting of the target relationships. A subsequent literature search utilized an amended procedure, which included studies that operationalized a hope-related variable in terms of Beck's Hopelessness Scale (BHS, Beck, \& Steer, 1988). Studies utilizing the BHS were selected because the conceptualization of hopelessness inherent in the BHS entails a cognitive/affective structure that mirrors the structure inherent in Snyder's hope theory (Kao, Liu, \& Lu, 2012). 
With the addition of the BHS criterion, two additional studies were identified. The inclusion of these studies brought the number of total studies investigated in this meta-analysis to ten $(N=2387)$. Seven studies reported product moment coefficients for the relationships between anxious attachment and hope, and for the relationships between avoidant attachment and hope, and six studies reported product moment coefficients for the relationship between secure attachment and hope (see Table 1 for primary studies).

\subsection{Coding}

Stock's (1994) six coding categories provided the framework for coding decisions. Studies were reviewed and coded for publication status, study setting, participant sample characteristics, methodology and interpretability of effect size by the lead author of this meta-analysis and a University of Wisconsin-Madison Rehabilitation Psychology graduate student. Because all studies included are cross-sectional field studies, they were not coded for design-type, treatment effect, or method of group assignment. Inter-rater reliability was calculated with the Kappa function included in the MAc R software package and indicated substantial agreement $(k=.79)$. It should be noted that the coding manual was developed and coding was completed for the eight original studies prior to the identification of the BHS studies, therefore the BHS articles were coded separately with the lead author of the meta-analysis as the only coder, and are not represented in inter-rater reliability findings.

\subsection{Effect Size Calculation}

In order to convert outcome data reported in the ten primary studies to a common metric, aggregated effect sizes were calculated for each study. Two primary studies reported hope-related scores in terms of the trait hope scale (Snyder et al., 1991). The THS is a multidimensional self-report instrument that individuals' levels on two hope constructs: 1) agency thoughts and 2) pathways thoughts (Snyder, 1994). One primary study reported separate coefficients for securemother-attachment and secure father-attachment, and early adolescent hope and middle adolescent hope (Sim \& Yow, 2011). For these studies, the agg function included in the MAc R software package was utilized to aggregate the agency and pathways scores to a unidemensional hope score; and mother attachment and father attachment to a single secure attachment score. Early adolescents and middle adolescents were aggregated to a single group. Additionally, BHS scales were reverse-coded to coincide with the hopeoriented scales (see Table 1 for complete instrumentation of primary studies; Table 2 for within-study aggregation). Following within-study aggregation, the omni function included in the MAc R software package was utilized to calculate a random effects model omnibus effect size $(r)$ for the relationships between anxious attachment and hope $(k=7)$, avoidant attachment and hope $(k=7)$ and secure attachment and hope $(k=6)$.

\subsection{Analysis}

In addition to identification of aggregated effect size for each relationship of interest, goals of this meta-analysis include assessment of the between-study homogeneity of the primary datasets, and investigation of potential sources of the heterogeneity. Historically, between-study heterogeneity has been reported in terms of the $Q$ statistic, which follows the chi-square distribution ( $\mathrm{df}=k-1)$ and provides a binary indication of heterogeneity; however, contemporary methodologists have advocated for use of the $I^{2}$ statistic, which provides an assessment of the extent of homogeneity and is reported as a percentage of variance due to systematic error. Assessment of the relative presence of study heterogeneity contributes to the interpretability of results by providing an account of the proportion of outcome data that reflects true effects, and the proportion that is an artifactual reflection of variation between studies (Huedo-Medina, Sánchez-Meca, Marín-Martínez, \& Botella, 2006). In this metaanalysis, the omni function included in the MAc R software package was used to calculate the omnibus $Q$ statistic and the omnibus $I^{2}$.

Where significant between-study heterogeneity is observed, moderator analysis is an appropriate approach to investigating potential sources. The MACAT function included in the MAc R software package was utilized for random effects analysis of three categorical moderators. Categorical moderators identified included 1) type of hope instrument utilized to assess the hope construct, 2) number of attachment factors assessed by the attachment instrument (anxious, avoidant and secure; anxious and avoidant only; or secure only), and 3) the use of incentive during participant recruitment. Clinical status of participant sample was considered as a fourth moderator, however because only one of the ten primary studies included a clinical sample, it was concluded that a 
Table 1. Study focus, sample, hope measures, attachment measures and zero order correlations.

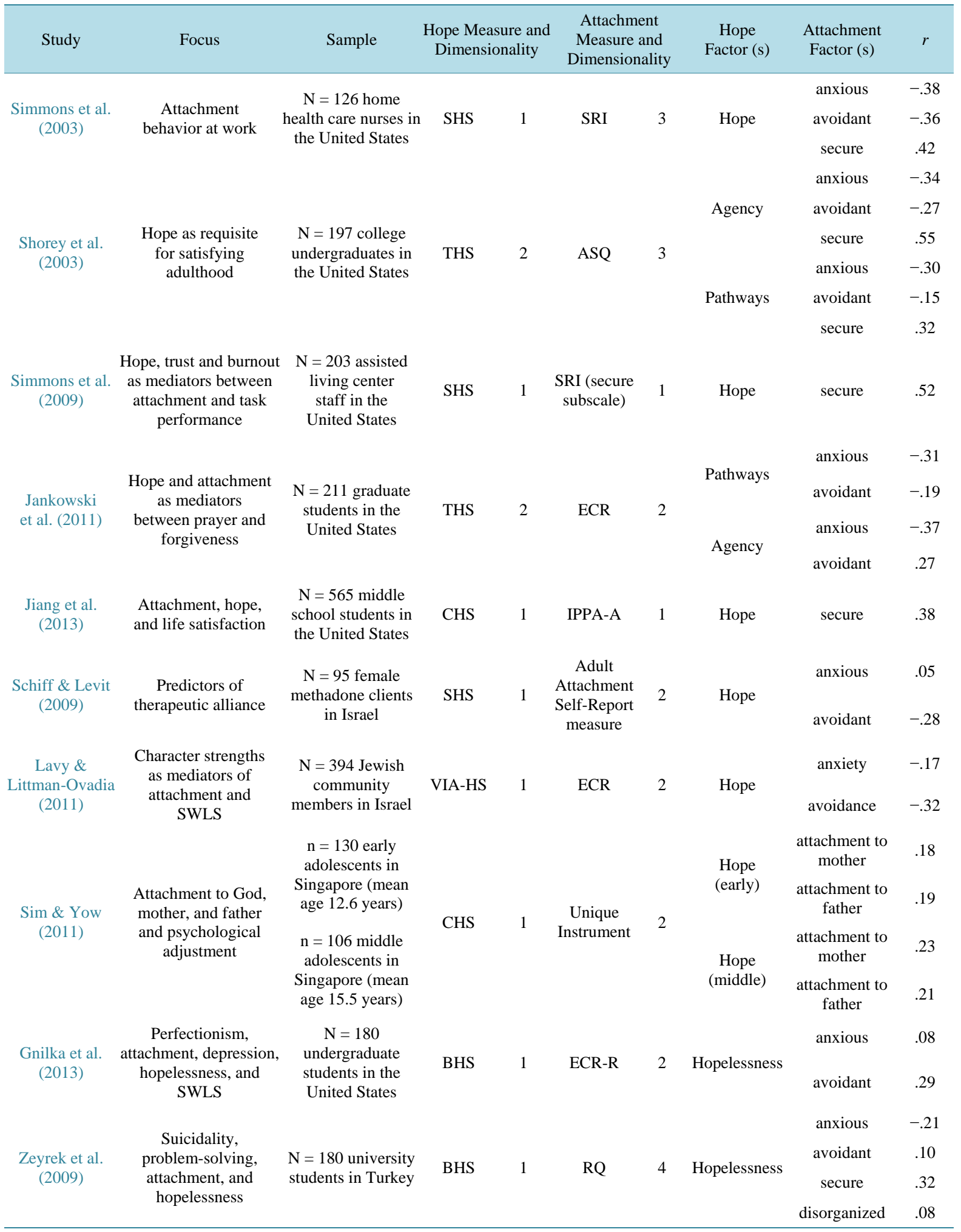

Note: ASQ = Attachment Style Questionnaire (Feeney et al., 1994); BHS = Beck Hopelessness Scale (Beck \& Steer, 1988); CHS = Children's Hope Scale (Snyder et al., 1997); SRI = Self-Reliance Inventory (Quick et al., 1996); SHS = State Hope Scale (Snyder et al., 1996); ECR = The Experiences in Close Relationships (Brennan et al., 1998); IPPA = The Inventory of Parent and Peer Attachment (Armsden \& Greenberg, 1987); THS = Trait Hope Scale (Snyder et al., 1991); VIA-IS = Values In Action Inventory of Strengths (Peterson \& Seligman, 2004). 
Table 2. Within-study aggregated effect sizes for hope and attachment relationships.

\begin{tabular}{|c|c|c|c|c|}
\hline Study & $\mathrm{N}$ & Hope construct & Attachment factor(s) & $r$ \\
\hline \multirow{3}{*}{ Simmons et al. (2003) } & \multirow{3}{*}{126} & \multirow{3}{*}{ State Hope } & anxious & -.38 \\
\hline & & & avoidant & -.36 \\
\hline & & & secure & .42 \\
\hline \multirow{3}{*}{ Shorey et al. (2003) } & \multirow{3}{*}{197} & \multirow{3}{*}{ Trait Hope } & anxious & -.35 \\
\hline & & & avoidant & -.23 \\
\hline & & & secure & .48 \\
\hline Simmons et al. (2009) & 203 & State Hope & secure & .52 \\
\hline \multirow{2}{*}{ Jankowski et al. (2011) } & \multirow[b]{2}{*}{211} & \multirow[b]{2}{*}{ Trait Hope } & anxious & -37 \\
\hline & & & avoidant & -.25 \\
\hline Jiang et al. (2013) & 565 & Children’s Hope & secure & .38 \\
\hline \multirow{2}{*}{ Schiff \& Levit (2009) } & \multirow{2}{*}{95} & \multirow{2}{*}{ State Hope } & anxious & .05 \\
\hline & & & avoidant & -.28 \\
\hline \multirow{2}{*}{ Lavy \& Littman-Ovadia (2011) } & \multirow{2}{*}{394} & \multirow{2}{*}{ VIA-S Hope } & anxious & -.17 \\
\hline & & & avoidant & -.32 \\
\hline Sim \& Yow $(2011)^{\mathrm{b}, \mathrm{c}}$ & 236 & Children's Hope & secure & .24 \\
\hline \multirow{2}{*}{ Gnilka et al. (2013) ${ }^{\mathrm{d}}$} & \multirow{2}{*}{180} & \multirow{2}{*}{ Hopelessness } & anxious & -.08 \\
\hline & & & avoidant & -.29 \\
\hline \multirow{2}{*}{ Zeyrek et al. (2009) ${ }^{\mathrm{d}}$} & \multirow[b]{2}{*}{180} & \multirow[b]{2}{*}{ Hopelessness } & anxious & -.21 \\
\hline & & & avoidant & .10 \\
\hline
\end{tabular}

Note: ${ }^{a}$ Agency/pathways aggregation reflects .71 correlation (Snyder, et al., 1994); ${ }^{\mathrm{b}}$ Attachment to mother/attachment to father aggregation reflects .66 correlation (Sim \& Yow, 2011); ${ }^{\mathrm{c} E a r l y}$ adolescent/middle adolescent aggregation reflects pooled sample; ${ }^{\mathrm{d}}$ BHS scales were reverse-coded to coincide with the hope scales; $r$ = Pearson product-moment correlation.

clinical status moderator could not yield meaningful results. No continuous moderators were coded for this meta-analysis.

A range of research questions is represented across the ten studies included in this meta-analysis, however, because the current study is focused on findings specific to the hope/attachment relationship, only correlational findings related to the relationship between hope and attachment are investigated. Each of the ten primary studies reported correlational findings in terms of the product-moment coefficient (Pearson's $r$ ). Therefore, while completion of statistical applications involved Fisher's $z$ transformation, all reported correlational findings have been converted back to Pearson's $r$.

\subsection{Results}

Table 3 summarizes omnibus results of the relationship between the unitary hope construct and the three dimensions of attachment. Aggregated effect sizes for the relationships between hope and anxious attachment, hope and avoidant attachment, and hope and secure attachment were statistically significant and therefore supported the alternative hypothesis that correlational data is consistent with a relationship in which attachment style is predictive of levels of hope. The relationship between secure attachment scores and hope scores was the most robust relationship in the aggregated data $(r=.39)$. The relationships between hope and anxious attachment, and hope and avoidant attachment were smaller and similar ( $r s=-.22$ and -.23 , respectively). Because the $95 \% \mathrm{CI}$ does not include 0 , aggregate effect sizes for all three relationships differed significantly from $0(p<.05)$.

Heterogeneous effect sizes for the relationships provided the impetus for moderator tests to determine if the 
Table 3. Meta-analysis: aggregate effect sizes for relationship between attachment factors and hope.

\begin{tabular}{cccccccccc}
\hline Attachment factor & $k$ & $r$ & $95 \%$ CI & $p$ & $Q$ & $d f$ & $Q p$ & $I^{2}$ \\
\hline Anxious Attachment & 7 & -.22 & -.33 & -.12 & .0001 & 24.50 & 6 & .0004 & $76 \%$ \\
Avoidant Attachment & 7 & -.23 & -.34 & -.12 & .0001 & 26.91 & 6 & .0002 & $78 \%$ \\
Secure Attachment & 6 & .39 & .31 & .44 & $<.0001$ & 15.58 & 5 & .008 & $69 \%$ \\
\hline
\end{tabular}

Note: Studies were modeled as random effects, $k=$ number of studies, $r=$ effect size (aggregate correlation between hope and attachment dimension); $Q=$ homogeneity test; $p=$ probability value for $Q$ statistic under $\mathrm{H}_{0}(d f=k-1) ; I^{2}=$ percentage of variance in effect sizes that is attributable to systematic variation.

observed strength of the relationships varied according to identifiable characteristics of the primary studies (see $Q$ statistics in Table 3). Because the alternative hypothesis of the current study is rooted in investigation of the theoretical relationship between attachment styles and levels of hope, distinct effects of the specific assessment instrument sutilized in the primary studies to measure attachment and hope are of particular interest and were investigated. Further, because Snyder's model is often conceptualized as a motivational model (e.g., Chan et al., 2013), effects related to the use of incentive during participant recruitment were investigated.

This meta-analysis is comprised of a small number of studies, which may have contributed to the failure of two moderators to achieve statistical significance (see Table 4 for complete results). One moderator, use of incentive during sample recruitment was statistically significant $(Q=8.3, d f=1, p=.039)$. Scores on the secure attachment construct were a stronger predictor of hope scores in participant samples that were recruited through the use of an incentive, such as a gift card, extra-credit, or other compensation.

\section{Future Research and Study Limitations}

The goal of the present study has been to quantitatively assess the broad foundational tenets of the hope-attachment dynamic as described by Snyder (1994), in hopes of improving services to consumers through enhancing the theoretical knowledge base of helping professionals. Findings from the present meta-analysis provide justification for further quantitative investigation of hope as a mediator of attachment, with an eye toward assessing whether brief, targeted interventions, designed to increase individuals' levels of hope might provide psychosocial resources for consumers served by human service professionals. Results from this meta-analysis indicated that the relationship between levels of hope and secure attachment $(r=.39)$ was significantly more robust than the relationship between levels of hope and anxious attachment $(r=.22)$ or avoidant attachment $(r$ $=.23$ ). This finding seems consistent with accounts in the literature indicating that a dimensional-rather than a categorical-conceptualization of attachment yields more precise empirical accounts of individuals' internal working models and interpersonal relationship functioning. Future research focused on statistical testing of attachment variable type as moderator could provide useful information about the relationships between anxious, avoidant and secure attachment and individual's levels of hope. Moderator testing indicated statistically significant effects related to the use of an incentive during sample recruitment was significant. Researchers should be aware that including participant incentives in future study designs may affect outcome data.

While the central findings of this meta-analysis are optimistic, they should be interpreted with caution. The small cache of studies investigated limits the generalizability of findings. Data are reported in strictly correlational terms, with only theoretical justification for consideration of attachment as a predictor of hope. Furthermore, while the literature provides accounts of hope as construct that is amenable to therapeutic intervention, the present study does not investigate hope malleability. Additionally, while there are studies included in the extant literature that investigate hope as a potential mediator of relationships between attachment style and attachment-dependent outcomes, these investigations are not accounted for in the present study.

\section{Clinical Implications}

Results from this meta-analysis provide empirical support for the validity of the attachment/hope dynamic described by Snyder (1994) in which attachment style is predictive of individuals' levels of hope. Further, aggregate findings may have clinical relevance for individuals with maladaptive attachment style and clinicians who 
Table 4. Single-moderator analyses_-categorical moderators.

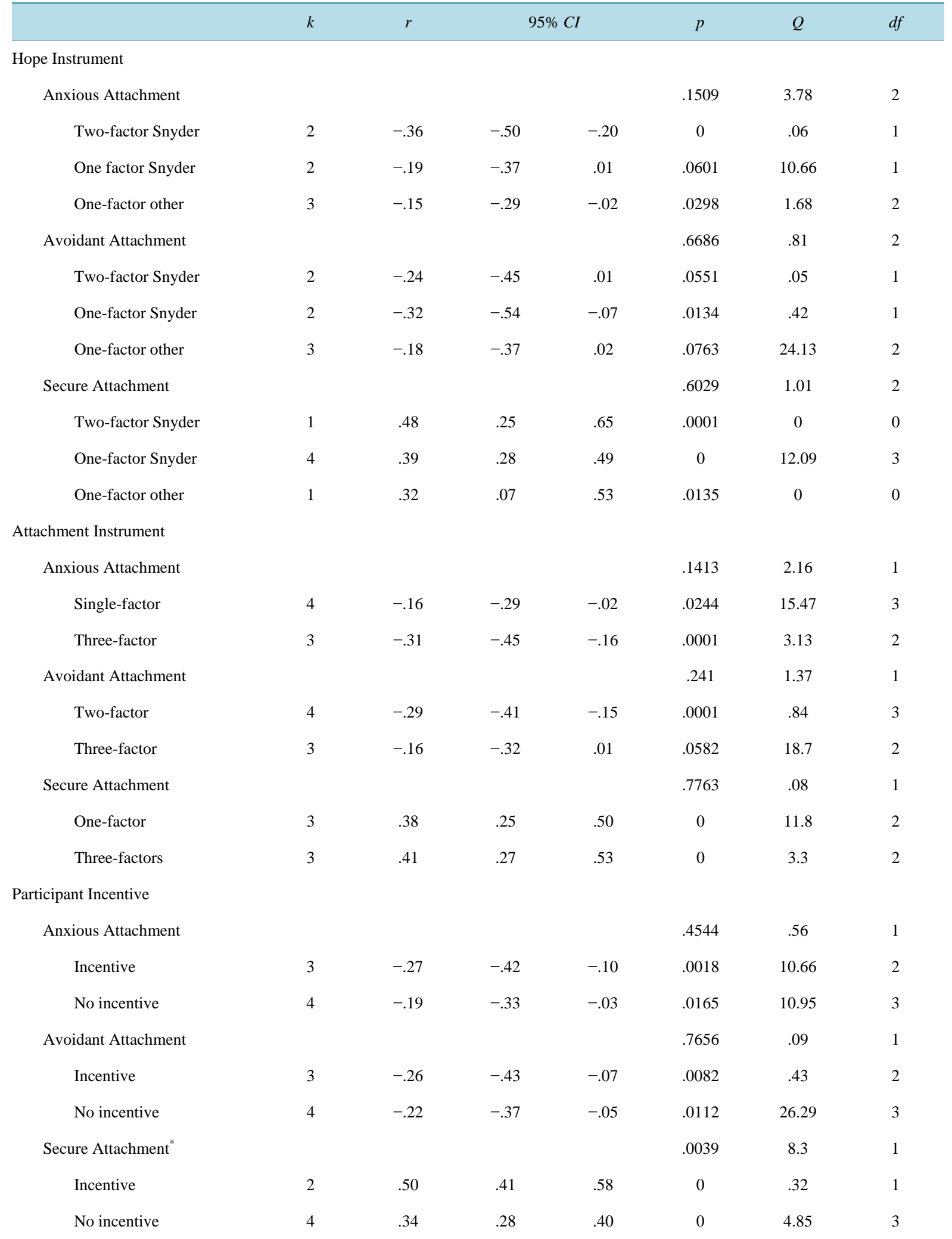

Note: Univariate analyses used a mixed model (studies random, levels of moderator variables fixed); $k=$ number of studies, $r=$ effect size; $Q$ for the moderator assesses homogeneity between groups; Qs for the levels assess homogeneity within groups; ${ }^{*}$ Statistically significant @.0039. 
strive to assist them. Most empirical accounts, including those cited in this meta-analysis, indicate that attachment is stable, traitlike, and predictive of a wide variety of outcomes that are relevant tohuman service consumers. Multiple studies have yielded estimates indicating that more than $40 \%$ of individuals among the general populationexperience insecure attachment (e.g., Diehl, Elnick, Bourbeau, \& Labouvie-Vief, 1998; Hazan \& Shaver, 1987). Consistent with the psychodynamic origins of the attachment construct, traditional attachmentfocused interventions hinge on conventional, prolonged psychotherapy, which is frequently impractical in contemporary human service settings (Olney, 2009; Livneh \& Sherwood, 1991).

Snyder's hope theory entails a newer model that incorporates central tenets of attachment theory. Quantitative-empirical investigation indicates that 1) individuals' levels of hope are related to manyhuman service-relevant outcome variables that are affected by attachment style; 2) individuals' levels of hope are malleable; and 3) brief, targeted, hope-based interventions often provide an effective means for increasing goal-directed thinking, adaptive coping, and improving a range of attachment-related outcomes (Chan et al., 2013; Davidson et al., 2012; Snyder et al., 2006). Therefore, interventions grounded in Snyder's hope theory may entail a pragmatic approach to therapeutic work that is well suited for assisting consumers with insecure attachment in clinical settings that require flexible, time-limited services.

\section{References}

Ainsworth, M. D. S., Blehar, M. C., Waters, E., \& Wall, S. (1978). Patterns of Attachment: A Psychological Study of the Strange Situation. Hillsdale, NJ: Erlbaum.

Ainsworth, M. D. S., \& Bowlby, J. (1991). An Ethological Approach to Personality Development. American Psychologist, 46, 333-341. http://dx.doi.org/10.1037/0003-066X.46.4.333

Bangert-Drowns, R. L. (1997). Some Limiting Factors in Meta-Analysis. In W. J. Bukoski (Ed.), Meta-Analysis of Drug Abuse Prevention Programs. National Institute on Drug Abuse Research Monograph 170 (pp. 234-250). Rockville: National Institute on Drug Abuse.

Beck, A. T., \& Steer, R. A. (1988). Manual for the Beck Hopelessness Scale. San Antonio, TX: Psychological Corporation.

Bowlby, J. (1969). Attachment and Loss, Vol. 1: Attachment. Attachment and Loss. New York: Basic Books.

Chan, Y.-C., Chan, F., Ditchman, N., Phillips, B., \& Chou, C. C. (2013). Evaluating Snyder's Hope Theory as a Motivational Model of Participation and Life Satisfaction for Individuals with Spinal Cord Injury: A Path Analysis. Rehabilitation Research Policy and Education, 27, 171-185. http://dx.doi.org/10.1891/2168-6653.27.3.171

Chan, F., Tarvydas, V., Blalock, K., Strauser, D., \& Atkins, B. J. (2009). Unifying and Elevating Rehabilitation Counseling Through Model-Driven, Diversity-Sensitive Evidence-Based Practice. Rehabilitation Counseling Bulletin, 52, 114-119. http://dx.doi.org/10.1177/0034355208323947

Cheavens, J. S., Feldman, D. B., Gum, A., Michael, S. T., \& Snyder, C. R. (2006). Hope Therapy in a Community Sample: A Pilot Investigation. Social Indicators Research, 77, 61-78. http://dx.doi.org/10.1007/s11205-005-5553-0

Davidson, O. B., Feldman, D. B., \& Margalit, M. (2012). A Focused Intervention for 1st-Year College Students: Promoting Hope, Sense of Coherence, and Self-Efficacy. The Journal of Psychology, 146, 333-352. http://dx.doi.org/10.1080/00223980.2011.634862

Diehl, M., Elnick, A. B., Bourbeau, L. S., \& Labouvie-Vief, G. (1998). Adult Attachment Styles: Their Relations to Family Context and Personality. Journal of Personality and Social Psychology, 74, 1656-1669. http://dx.doi.org/10.1037/0022-3514.74.6.1656

Dunn, D. S., \& Elliott, T. R. (2008). The Place and Promise of Theory in Rehabilitation Psychology. Rehabilitation Psychology, 53, 254-267. http://dx.doi.org/10.1037/a0012962

Fraley, R. C., Vicary, A. M., Brumbaugh, C. C., \& Roisman, G. I. (2011). Patterns of Stability in Adult Attachment: An Empirical Test of Two Models of Continuity and Change. Journal of Personality and Social Psychology, 101, 974-992. http://dx.doi.org/10.1037/a0024150

Gnilka, P. B., Ashby, J. S., \& Noble, C. M. (2013). Adaptive and Maladaptive Perfectionism as Mediators of Adult Attachment Styles and Depression, Hopelessness, and Life Satisfaction. Journal of Counseling \& Development, 91, 78-91. http://dx.doi.org/10.1002/j.1556-6676.2013.00074.x

Hazan, C., \& Shaver, P. (1987). Romantic Love Conceptualized as an Attachment Process. Journal of Personality and Social Psychology, 52, 511-524. http://dx.doi.org/10.1037/0022-3514.52.3.511

Huedo-Medina, T. B., Sánchez-Meca, J., Marín-Martínez, F., \& Botella, J. (2006). Assessing Heterogeneity in Meta-Analysis: Q Statistic or $I^{2}$ Index? Psychological Methods, 11, 193-206. http://dx.doi.org/10.1037/1082-989X.11.2.193

Jankowski, P. J., \& Sandage, S. J. (2011). Meditative Prayer, Hope, Adult Attachment, and Forgiveness: A Proposed Model. 
Psychology of Religion and Spirituality, 3, 115-131. http://dx.doi.org/10.1037/a0021601

Jiang, X. U., Huebner, E. S., \& Hills, K. J. (2013). Parent Attachment and Early Adolescents’ Life Satisfaction: The Mediating Effect of Hope. Psychology in the Schools, 50, 340-352. http://dx.doi.org/10.1002/pits.21680

Kao, Y. C., Liu, Y. P., \& Lu, C. W. (2012). Beck Hopelessness Scale: Exploring its Dimensionality in Patients with Schizophrenia. The Psychiatric Quarterly, 83, 241-255. http://dx.doi.org/10.1007/s11126-011-9196-9

Lavy, S., \& Littman-Ovadia, H. (2011). All You Need Is Love? Strengths Mediate the Negative Associations between Attachment Orientations and Life Satisfaction. Personality and Individual Differences, 50, 1050-1055. http://dx.doi.org/10.1016/j.paid.2011.01.023

Livneh, H., \& Sherwood, A. (1991). Application of Personality Theories and Counseling Strategies to Clients with Physical Disabilities. Journal of Counseling \& Development, 69, 525-538. http://dx.doi.org/10.1002/j.1556-6676.1991.tb02636.x

Lopez, F., Mauricio, A., Gormley, B., Simko, T., \& Berger, E. (2001). Adult Attachment Orientations and College Student Distress: The Mediating Role of Problem Coping Styles. Journal of Counseling and Development, 79, 459-464. http://dx.doi.org/10.1002/j.1556-6676.2001.tb01993.x

Lopez, S. J., \& Snyder, C. R. (Eds.). (2011). The Oxford Handbook of Positive Psychology. Oxford: Oxford University Press.

Olney, M. F. (2009). Effective Counseling Methods for Rehabilitation Counselors: Motivational Interviewing and Solution-Focused Therapy. Rehabilitation Education, 23, 233-244. http://dx.doi.org/10.1891/088970109805030020

Schiff, M., \& Levit, S. (2009). Correlates of Therapeutic Alliance and Treatment Outcomes among Israeli Female Methadone Patients. Research on Social Work Practice, 20, 380-390. http://dx.doi.org/10.1177/1049731509347854

Shorey, H. S., Snyder, C. R., Yang, X. D., \& Lewin, M. R. (2003). The Role of Hope as a Mediator in Recollected Parenting, Adult Attachment, and Mental Health. Journal of Social and Clinical Psychology, 22, 685-715.

http://dx.doi.org/10.1521/jscp.22.6.685.22938

Sim, T. N., \& Yow, A. S. (2011). God Attachment, Mother Attachment, and Father Attachment in Early and Middle Adolescence. Journal of Religion and Health, 50, 264-278. http://dx.doi.org/10.1007/s10943-010-9342-y

Simmons, B. L., Gooty, J., Nelson, D. L., \& Little, L. M. (2009). Secure Attachment: Implications for Hope, Trust, Burnout, and Performance. Journal of Organizational Behavior, 30, 233-247. http://dx.doi.org/10.1002/job.585

Simmons, B. L., Nelson, D. L., \& Quick, J. C. (2003). Health for the Hopeful: A Study of Attachment Behavior in Home Health Care Nurses. International Journal of Stress Management, 10, 361-375. http://dx.doi.org/10.1037/1072-5245.10.4.361

Snyder, C. R. (1994). Psychology of Hope: You Can Get Here from There. New York: Free Press.

Snyder, C. R. (2002). Hope Theory: Rainbows in the Mind. Psychological Inquiry, 13, 249-275. http://dx.doi.org/10.1207/S15327965PLI1304_01

Snyder, C. R., Harris, C., Anderson, J. R., Holleran, S. A., Irving, L. M., Sigmon, S. T., Yoshinobu, L. et al. (1991). The Will and the Ways: Development and Validation of an Individual-Differences Measure of Hope. Journal of Personality and Social Psychology, 60, 570-585. http://dx.doi.org/10.1037/0022-3514.60.4.570

Snyder, C. R., Lehman, K. A., Kluck, B., \& Monsson, Y. (2006). Hope for Rehabilitation and Vice Versa. Rehabilitation Psychology, 51, 89-112. http://dx.doi.org/10.1037/0090-5550.51.2.89

Stock, W. A. (1994). Systematic Coding for Research Synthesis. In H. Cooper, \& L. V. Hedges (Eds.), The Handbook of Research Synthesis (pp. 125-138). New York: Russell Sage.

Zeyrek, E. Y., Gençöz, F., Bergman, Y., \& Lester, D. (2009). Suicidality, Problem-Solving Skills, Attachment Style, and Hopelessness in Turkish Students. Death Studies, 33, 815-827. http://dx.doi.org/10.1080/07481180903142407 